МАЛЫШЕВ Михаил Львович - доктор социологических наук, профессор; ведущий научный сотрудник Института социологии Федерального научно-исследовательского социологического иентра Российской академии наук (117218, Россия, г. Москва, ул. Кржижановского, 24/35, корп. 5; anpi_2006@mail.ru)

УСПЕНСКАЯ Татьяна Николаевна - доктор экономических наук, руководитель Центра мониторинговых исследований Института дополнительного профессионального образования работников социальной сферы г. Москвы (105066, Россия, г. Москва, 1-й Басманный пер., 10; tuspenskaya@soceducation.ru)

\title{
МНОГОДЕТНЫЕ СЕМЬИ: СОЦИОЛОГИЧЕСКИЙ АНАЛИЗ ПРОБЛЕМ СОЦИАЛЬНОЙ ЗАЩИТЫ (на примере г. Москвы) 1
}

\begin{abstract}
Аннотация. Целью данной статьи является изучение проблем повышения роли семьи в обществе, стимулирования деторождения, улучшения социально-экономических условий жизнедеятельности многодетных семей, повышения уровня и качества их жизни. Приводимые результаты исследования отражают, прежде всего, специфику г. Москвы, но они значимы и в общероссийском плане.

Информационную базу статьи составляют данные социологического опроса 2110 респондентов из г. Москвы. Полученные результаты сформулированы в виде предложений в сфере материального обеспечения, здоровья и медицинского обслуживания, образования, социального обеспечения, досуга, обеспечения жильем.
\end{abstract}

Ключевые слова: многодетная семья, город, регион, льготы, материальное обеспечение, жилье, трудовая занятость, охрана здоровья, образование, социальное обслуживание, досуг

$\Pi$ роблема эффективности социальной политики в отношении многодетных семей в России - одна из самых актуальных. Поскольку в нашей стране проживают разные народности со своими обычаями, каждый субъект федерации имеет право толковать понятие многодетности в соответствии с принятыми на территории культурными традициями. Большинство регионов считают таковыми родителей, состоящих в законном браке, имеющих 3 и более детей, собственных или усыновленных. Дети должны быть несовершеннолетними (до 16 лет по Москве, до 18 - по другим субъектам федерации) или до 23-летнего возраста, если они обучаются по очной форме в высших и средних специальных учреждениях.

В Российской Федерации проводится активная политика по улучшению социальной поддержки и созданию благоприятных условий для жизни многодетных семей [Маркин 2017: 82-87]. Так, в последние годы в России принят ряд нормативно-правовых актов, направленных на поддержку семьи, материнства, отцовства и детства.

Сегодня государственная помощь семьям с детьми оказывается, прежде всего, в денежном эквиваленте: выплаты на детей в связи с их рождением, содержанием и воспитанием (пенсии, пособия). Кроме того, граждане, имеющие детей, получают трудовые, социальные, налоговые, жилищные, медицинские, кредитные и другие льготы.

Тем не менее, по нашему мнению, существует проблема разрозненности мероприятий, направленных на укрепление института семьи. Одних экономи-

\footnotetext{
1 Статья подготовлена на основе данных экспресс-исследования «Актуальные проблемы многодетных семей», проведенного Центром мониторинговых исследований ИДПО ДТСЗН г. Москвы совместно с ОО «Объединение многодетных семей города Москвы» и Центром региональной социологии и конфликтологии Института социологии РАН. Исследование проводилось в декабре 2016 г.
} 
ческих и финансовых инструментов явно недостаточно для повышения роли семьи в обществе, стимулирования деторождения. Государство и семья должны стать партнерами, взаимно разделяющими риски и ответственность за благополучие как отдельной семьи, так и государства в целом. Это основные постулаты принятой в августе 2014 г. Концепции государственной семейной политики в Российской Федерации на период до 2025 года ${ }^{1}$.

Московские социальные службы считают первоочередным долгом города заботу о многодетных семьях. В столице принят и действует закон города Москвы «О социальной поддержке семей с детьми в городе Москве» ${ }^{2}$, направленный на создание условий для повышения уровня жизни семей с детьми, включая многодетные семьи, и регулирующий отношения по предоставлению им денежных выплат и других мер социальной поддержки.

Число многодетных семей в Москве ежегодно увеличивается почти на $10 \%$. По данным Департамента труда и социальной защиты населения города Москвы, в феврале 2015 г. в Москве проживали 101989 многодетных семей, а в феврале 2016 г. их число составило уже 111864 семей $^{3}$.

Для изучения актуальных вопросов многодетных семей в целом, анализа мнений многодетных семей с точки зрения проблем их занятости, здоровья, образования, социального обслуживания и обеспечения жильем, а также других особенностей их жизнедеятельности было проведено социологическое исследование «Актуальные проблемы многодетных семей». Приведем некоторые данные, полученные в результате этой работы.

Так, наиболее актуальными проблемами многодетных семей респонденты считают, во-первых, обеспечение жильем и материальные выплаты и компенсации. Следующей по актуальности проблемой является качество охраны здоровья и медицинского обслуживания, это отмечают более четверти $(27,5 \%)$ участников опроса. Далее идут качество образовательных программ и трудовая занятость. Вопросы социального обслуживания, организации досуга и обеспечения транспортом респонденты считают менее значимыми по сравнению с перечисленными выше.

Анализ ответов респондентов свидетельствует, что степень важности проблем обеспечения жильем, социального обслуживания, трудовой занятости, транспортного обеспечения, охраны здоровья и медицинского обслуживания повышается с увеличением числа детей в составе семьи.

Наиболее часто встречающиеся запросы респондентов сводятся к решению проблем предоставления жилья или компенсации на оплату (аренду) жилого помещения, бесплатного проезда для обоих родителей, предоставления льгот, особенно образовательных (бесплатные дополнительные услуги в дошкольных учреждениях и в школе, предоставление льгот при поступлении в вуз и при получении высшего образования), а также льгот по организации летнего отдыха. Респонденты не оставили без внимания и важность льгот на осуществление досуговой деятельности - посещение театров, музеев.

Еще один аспект, на который респонденты обратили внимание, это необходимость предоставления льгот всем многодетным семьям независимо от того, имеют они статус малообеспеченных или нет.

Анализ материалов опроса и высказанных респондентами предложений определяет, по нашему мнению, необходимость дифференциации их проблем в

\footnotetext{
${ }^{1}$ Концепция государственной семейной политики в Российской Федерации на период до 2025 года. Доступ: https://rg.ru/2014/08/29/semya-site-dok.html// (проверено 09.03.2018).

2 Закон города Москвы «О социальной поддержке семей с детьми в городе Москве» от 23.11.2006 № 60 (с изм. на 28.12.2016). Доступ: http://docs.cntd.ru/document/3662941// (проверено 03.03.2018).

3 http://www.dszn.ru/news/smi/18413/
} 
зависимости от состава и структуры семьи, выделения приоритетов и создания комплекса мер по решению наиболее актуальных проблем.

Рассмотрим наиболее актуальные из них.

1. Обеспечение жильем. Выстраивая рейтинг наиболее актуальных для многодетных семей вопросов, на 1-е место респонденты поставили проблему обеспеченности жильем.

Жилищный вопрос является первостепенной проблемой, т.к. абсолютно каждому члену семьи для нормального функционирования необходимо личное пространство. Конечно же, стоит сказать и об уровне благоустройства, которое требует массу вложений - как материальных, так и моральных [Грудина 2014; Казибекова, Исмиева 2015]. Социологические исследования показывают, что у $46 \%$ населения основные конфликты в семье разгораются на фоне совместного проживания с родителями супруга и из-за нехватки личного пространства.

Что же необходимо предусмотреть для улучшения жилищных условий многодетных семей? Две трети респондентов сориентированы на формы решения жилищной проблемы незамедлительного характера: субсидирование жилищной ипотеки $(66,9 \%)$ и выделение участков под строительство, садовых участков за пределами города $(63,4 \%)$.

Вместе с тем более половины многодетных семей, в составе которых проживают более 3 несовершеннолетних детей или ребенок-инвалид $(56,4 \%)$, видят решение жилищной проблемы в предоставлении жилых помещений в соответствии с санитарными нормами на основе социального найма.

Только около $1 / 4(23,7 \%)$ участников опроса выступают за выделение жилого дома за пределами города взамен имеющегося жилья. Среди этой группы респондентов абсолютное большинство (90\%) тех, кто выступает за развитие гибких форм занятости, и более половины (52\%) поддерживающих самозанятость на основе семейных предприятий.

Таким образом, жилищные проблемы многодетных семей, по нашему мнению, должны решаться комплексно с учетом многих факторов, активно влияющих на их жизнедеятельность, таких как материальное обеспечение, занятость, социальная и транспортная инфраструктура.

2. Материальное положение и трудовая занятость. С целью выявления мер, способствующих улучшению социально-экономического положения многодетных семей, респондентам был задан вопрос: «Как Вы считаете, какие меры необходимо предусмотреть для повышения устойчивости материального положения многодетных семей?»

Безусловным лидером стал вариант ответа «социальные доплаты к пособиям на ребенка до прожиточного минимума» - 72,5\%. На 2-е место респонденты поставили создание гибких финансовых инструментов (льготные кредиты, субсидии, ценные бумаги) - 49,9\%. На 3-м месте стоят меры, которые предполагают создание условий для гарантированной трудовой занятости одного из родителей и совершеннолетних детей из многодетных семей $(48,8 \%)$, а также пособия $(48,3 \%)$.

Заслуживают интереса и другие варианты ответов. Так, на 5-е и 6-е места по значимости мер повышения устойчивости материального положения заняли: «возможность выхода на пенсию одного из родителей при достижении третьим из детей 16 лет» и «создание механизмов формирования накопительных лицевых счетов на третьего ребенка и последующих детей в семье за счет бюджетных средств» - 36,9\% и 25,9\% соответственно. На последнем (7-м) месте - «субсидирование расходов на услуги “замещающей мамы”, няни» $-19,2 \%$.

Таким образом, по приоритетности практически $3 / 4$ респондентов считают 
ответственным за устойчивость материального положения многодетных семей государство и предлагают в качестве способа его обеспечения прямое патерналистское воздействие государственных органов за счет доведения социальных доплат к пособиям на ребенка до прожиточного минимума [Карданова 2016; Рубаненко 2017].

Около половины участников опроса видят гарантом стабильности социально ориентированное бизнес-сообщество, способное обеспечить эффективное инвестирование государственных средств или льготное кредитование в интересах многодетных семей, а также гарантирующее трудовые преференции родителям и совершеннолетним детям из данных семей. Указанное в целом отражает иждивенческое поведение, не ориентированное на активное участие и ответственность получателя помощи за свое благосостояние.

Что же касается трудовой занятости, то ответы на вопрос: «По Вашему мнению, какие формы занятости и меры по ее обеспечению наиболее предпочтительны для членов многодетных семей?» - в целом свидетельствуют, что значительная доля $(87,9 \%)$ респондентов отдают свое предпочтение гибким формам занятости (неполный рабочий день или неделя, надомная работа, дистанционная занятость др.).

Особого внимания заслуживает тот факт, что $42 \%$ участников опроса предпочли бы самозанятость на основе семейных предприятий (малый бизнес, предпринимательство и т.д.): эта группа респондентов занимает по численности 2-е место. Традиционное представление о занятости - работа на постоянной основе по прежнему месту работы - разделяют более $1 / 3(36,9 \%)$ опрошенных. На 4-м месте респонденты, предпочитающие временную занятость (сезонная, на период выполнения определенного проекта, др.), их менее трети - 28,2\%. Более $1 / 4(26,9 \%)$ участников опроса в качестве меры по обеспечению трудовой занятости видят проведение специализированных тематических ярмарок вакансий для родителей и детей трудоспособного возраста из многодетных семей. Необходимо также отметить, что не планируют работать в будущем около $1 / 3$ респондентов $(30,4 \%)$.

3. Охрана здоровья и медицинское обслуживание. По результатам данного исследования респонденты поставили вопросы охраны здоровья и медицинского обслуживания многодетных семей в рейтинге по значимости на 3-е место.

Для конкретизации мнений респондентов по указанной проблематике был задан вопрос: «По Вашему мнению, какие вопросы охраны здоровья и медицинского обслуживания требуют особого внимания?»

Практически 2/3 (62,8\%) опрошенных на 1-е место поставили необходимость оформления договора добровольного медицинского страхования в пользу членов многодетных семей за счет государства. Немного меньшее число респондентов $(59,6 \%)$ высказались за новую организационную форму предоставления медицинских услуг «Семейный доктор многодетной семьи».

Более половины $(50,6 \%)$ респондентов выступают за необходимость проведения ежегодной диспансеризации и диагностического обследования родителей многодетной семьи, а 46,4\% опрошенных - за развитие стационаро- и амбулаторозамещающих технологий оказания медицинской помощи на дому с применением мобильных медицинских бригад (забор анализов, диагностика и др.).

Анализ ответов на данный вопрос в разрезе состава семей по числу детей свидетельствует, что за инновационно-организованные формы с преимущественным предоставлением медицинских услуг на дому в основном выступают респонденты, в чьих семьях воспитываются более 5 детей и ребенок с инвалидностью. Таким образом, как минимум каждый второй участник 
опроса отметил важность для многодетных семей всех перечисленных выше аспектов охраны здоровья и медицинского обслуживания и привлечения особого внимания к разработке и внедрению новых форм медицинского обслуживания этих семей.

4. Образование. С целью учета мнений представителей многодетных семей при реализации образовательной политики столицы респондентам был задан вопрос: «Какие образовательные услуги и программы необходимо ввести для многодетных семей?» Были предложены 4 варианта ответа.

$79,2 \%$ респондентов отметили важность введения программ дополнительного образования, способствующих повышению уровня социальной мобильности (иностранные языки, компьютерная грамотность и др.).

Трудовые навыки и востребованность их на рынке труда, как отмечалось ранее, являются основой устойчивого развития и высокого уровня благосостояния многодетных семей. Так, каждый второй опрошенный $(52,3 \%)$ считает, что необходимо ввести специальные программы для членов многодетных семей трудоспособного возраста в службах занятости для их подготовки и переподготовки по другим профессиям.

Две пятых $(40,1 \%)$ общего числа опрошенных считают, что многодетным семьям нужны программы социальной и психолого-педагогической грамотности (конфликтология, родительско-детские, супружеские отношения и др.).

Необходимость программ, повышающих уровень экономической грамотности с целью обеспечения безопасности членов многодетной семьи при пользовании финансовыми (банковскими, инвестиционными и др.) инструментами, продуктами и услугами, отметили чуть более $1 / 3(35,4 \%)$ принявших участие в опросе.

5. Социальное обслуживание. Проведенные ранее исследования свидетельствуют, что на данном этапе развития многодетная семья не является в нашей стране объектом прямой социальной защиты [Коломасова, Зоткина 2017; Рубаненко 2017]. Действующее в этой сфере законодательство как на федеральном, так и на региональном уровне предполагает лишь такие формы, при которых члены многодетной семьи «набирают» различные виды помощи по принципу «меню», главным образом через систему разного рода пособий. При реализации этого принципа не учитывается синергетический эффект, играющий отрицательную роль, а потому многодетная семья в условиях модернизационных процессов, неизбежно порождающих кризисные черты, становится группой социального риска.

Недостаточный уровень материального обеспечения многодетных семей заставляет каждого второго из них в качестве ответа на вопрос: «Что, по Вашему мнению, необходимо изменить в социальном обслуживании многодетных семей?» - предлагать проводить мониторинг социально-экономического положения многодетных семей и их потребностей в социальных услугах $(51,8 \%)$.

Две пятых $(42,1 \%)$ общего числа респондентов выступают за развитие инновационных технологий социального обслуживания, обеспечивающих комфортное пребывание в домашней среде несовершеннолетних, среди которых выделяют семейный детский сад, семейную школу, услугу «передышки» и др.

Для обеспечения реализации указанных выше мер каждый третий $(36,7 \%)$ участник опроса считает необходимым повышение профессионализма кадров социальных служб для работы с многодетными семьями.

Высока доля респондентов (более четверти - 25,6\%), которые осознают необходимость организационной помощи со стороны органов управления и 
организаций социального обслуживания по формированию и организационнометодическому сопровождению деятельности групп самопомощи многодетных семей.

Также $1 / 4$ опрошенных $(25,2 \%)$ выступают за специализацию социального обслуживания многодетных семей через закрепление участкового социальнопедагогического работника, обеспечивающего социальное сопровождение.

Среди аргументированных предложений респондентов следует выделить следующие:

- необходимо повысить роль социально ориентированных некоммерческих организаций (объединений) (COHКО) в процессе оказания помощи семьям;

- разработать эффективную информационную политику по вопросам предоставления мер социальной поддержки и социального обслуживания (сайты, информационные порталы и др.).

Таким образом, анализ ответов респондентов свидетельствует о необходимости создания в деятельности системы социальной защиты населения отдельного направления социального обслуживания, объектом которого должны быть исключительно многодетные семьи, а также применения инновационных технологий обслуживания семей и повышения профессионального уровня специалистов учреждений, предоставляющих социально-педагогические и иные услуги многодетным семьям.

6. Организация досуга. Досуговая деятельность направлена на обеспечение отдыха, развитие талантов, реализацию собственных увлечений. Доступность социокультурных и спортивно-рекреационных ресурсов оказывает большое влияние на гармоничное существование членов многодетных семей, способствует духовному единению и преодолению межпоколенческих и внутрисемейных конфликтов.

На вопрос: «Какие направления досуга, по Вашему мнению, нуждаются в развитии?» - участники исследования дали следующие ответы.

На 1-е место из предложенных вариантов ответов более $4 / 5$ респондентов $(83,5 \%)$ поставили «наличие системы абонементов для многодетных семей в музеи, театры, кинотеатры, парки культуры и др.». Данная мера гарантирует многодетным семьям возможность посещения досуговых мероприятий, в отличие от билетов (зачастую бесплатных) на заранее не определенные даты. Абонементы снижают как материальные, так и временные расходы многодетных семей.

Около $2 / 3$ участников опроса $(64,6 \%)$ считают, что в досуговой сфере следует уделять особое внимание развитию системы массового творчества для занятий членов многодетных семей (дома культуры, кружки по месту жительства и пр.); $61,7 \%$ выбрали ответ «создание возможности и доступности для многодетных семей занятий физкультурой, социальным туризмом, наличие рекреационных зон (зон отдыха)».

Анализ ответов на вопрос о направлениях досуга, нуждающихся в развитии, свидетельствует, что респонденты в большей степени рассчитывают, что субсидирование их расходов на досуговую деятельность и отдых будет осуществляться государством.

Приведенные выше проблемы определяют необходимость разработки комплекса мер по их решению с использованием дифференцированного подхода и на основе формирования мероприятий адресного характера в зависимости от структуры и состава многодетных семей.

Роль государственной социальной политики в области увеличения денежных доходов и роста заработной платы является важной для улучшения материального положения и социального самочувствия многодетных семей. В связи 
с этим необходимо заменить «стратегию выживания» многодетной семьи на «стратегию развития». Это, по нашему мнению, может быть достигнуто следующим образом.

В сфере обеспечения жильем:

- разработка и внедрение правовых и финансовых механизмов предоставления банками целевых кредитов на улучшение жилищных условий семьям при рождении четвертого и каждого последующего ребенка с прогрессивной шкалой погашения процентов по банковским кредитам или подлежащих возврату сумм за счет государства в зависимости от числа детей в возрасте до 18 лет или до 23 лет, если они обучаются в образовательном учреждении по очной форме;

- разработка и внедрение правовых и финансовых механизмов компенсации многодетным семьям части затрат на приобретение или строительство жилья, предоставление строительных материалов для индивидуального жилищного строительства в случае рождения (усыновления) ребенка;

- выделение жилого дома, обеспеченного комплексом социальной, экономической, транспортной, инженерной инфраструктуры, на территории Новой Москвы взамен имеющегося жилья.

В сфере материального обеспечения и трудовой занятости:

- установление социальных доплат к пособиям на ребенка до уровня прожиточного минимума;

- создание гибких форм занятости (неполный рабочий день или неделя, надомная работа, дистанционная занятость, др.);

- разработка и реализация направления государственной программы, обеспечивающего самозанятость членов многодетных семей на основе семейных предприятий (малый бизнес, предпринимательство и т.д.);

- установление преимущественного права на получение рабочего места многодетными родителями в случае соответствия работника квалификационным и профессиональным требованиям вакансии и успешного прохождения испытаний (конкурса) при приеме на работу при прочих равных условиях;

- разработка и реализация мер по развитию гибких финансовых инструментов (льготные кредиты, субсидии, ценные бумаги) для многодетных семей;

- разработка и реализация мер налогового стимулирования работодателей к принятию на работу работников, являющихся многодетными родителями;

- законодательное установление для многодетных семей регрессивной системы налогообложения, учитывающей общесемейный доход и число детей в семье.

В сфере охраны здоровья и медицинского обслуживания:

- стимулирование работодателей на заключение договора добровольного медицинского страхования в пользу работника - члена многодетной семьи;

- введение специализированной организационной формы предоставления медицинских услуг «Семейный доктор многодетной семьи»;

- ежегодная диспансеризация и диагностическое обследование родителей многодетной семьи;

- развитие стационаро- и амбулаторозамещающих технологий оказания медицинской помощи на дому с применением мобильных медицинских бригад (забор анализов, диагностика и др.).

В сфере образования:

- внедрение организационно доступных и инновационных форм получения образования (дистанционное обучение, обучение в период отпуска по беременности и отпуска по уходу за ребенком); 
- формирование информационных баз бесплатных образовательных программ и создание ресурсных центров, их реализующих;

- внедрение программ дополнительного образования, способствующих повышению уровня социальной мобильности (иностранные языки, компьютерная грамотность и др.);

- внедрение программ дополнительного образования по повышению уровня экономической грамотности с целью обеспечения безопасности членов многодетной семьи при пользовании финансовыми (банковскими, инвестиционными и др.) инструментами, продуктами и услугами;

- введение программ обучения социальной и психолого-педагогической грамотности (конфликтология, родительско-детские, супружеские отношения и др.) в деятельность учреждений социального обслуживания;

- введение специальных программ подготовки и переподготовки для членов многодетных семей трудоспособного возраста в службах занятости.

В сфере социального обслуживания:

- проведение мониторинга социально-экономического положения многодетных семей и их потребностей в социальных услугах;

- выделение в отдельное направление деятельности организаций социального обслуживания, оказывающих социальные услуги многодетным семьям;

- введение инновационных технологий социального обслуживания, таких как участковая семейная служба, семейный детский сад, семейная школа, услуга «передышки» и др.

- развитие форм самопомощи многодетных семей;

- подготовка, переподготовка и повышение квалификации специалистов по программам «Работа с многодетной семьей»;

- разработка эффективной информационной политики по вопросам предоставления мер социальной поддержки и социального обслуживания (сайты, информационные порталы и др.).

В сфере организации досуга:

- развитие семейных форм организации проведения досуга на базе учреждений социальной инфраструктуры (семейные театры, спартакиады, семейный туризм и др.);

- гарантированность бесплатного использования досуговых ресурсов организаций социальной инфраструктуры;

- рассмотрение возможностей компенсации расходов многодетных семей на проезд к местам отдыха и оздоровления.

\section{Список литературы}

Грудина Т.Н. 2014. Социологический портрет многодетной семьи в России. - Семья и социально-демографические исследования: научный интернет-журнал. № 4. Доступ: http://demographia.net/journal (проверено 20.06. 2018).

Казибекова Н.А., Исмиева 3.М. 2015. Актуальные проблемы многодетных семей и семей с детьми-инвалидами. - Наука и мир. Т. 3. № 5. С. 26-28.

Карданова И.В. 2016. Проблемы правового регулирования предоставления пособий многодетным семьям в субъектах Российской Федерации. - Право и практика. № 2. С. 115-122.

Коломасова Е.Н., Зоткина Я.А. 2017. Социально ориентированные некоммерческие организации как субъект помощи многодетным семьям. - Теоретические и практические аспекты развития научной мысли в современном мире: сборник материалов международной научно-практической конференции. В 4 ч. Екатеринбург: Аэтерна. С. 219-222.

Маркин В.В. 2017. Социальное пространство России в региональном изме- 
рении: социологический анализ, моделирование, мониторинг. - Россия и мир: глобальные вызовы и стратегии социокультурной модернизации: материалы международной научно-практической конференции. Москва, 12-13 октября 2017 г. (отв. редактор А.В. Тихонов). М.: ФНИСЦ РАН.

Рубаненко А.В. 2017. Государственная социальная помощь многодетным семьям в России. - Современные социально-экономические процессы: проблемы, закономерности, перспективы: сборник материалов III Международной научнопрактической конференции. В 2 ч. С. 217-219.

MALYSHEV Mikhail L'vovich, Dr.Sci. (Soc.), Professor, Leading Researcher of the Sociological Institute - branch of the Federal Center of Theoretical and Applied Sociology, Russian Academy of Sciences (bld. 5, 24/35 Krzhizhanovskogo St, Moscow, Russia, 117218; anpi_2006@mail.ru)

USPENSKAYA Tatyana Nikolaevna, Dr.Sci. (Econ.), Head of the Research Center for Monitoring, Institute for Additional Professional Education of Social Workers (10 15t Basmannyi Lane, Moscow, Russia, 105066; tuspenskaya@ soc-education.ru)

\section{LARGE FAMILIES: A SOCIOLOGICAL ANALYSIS OF THE PROBLEMS OF THEIR SOCIAL PROTECTION (ON THE EXAMPLE OF MOSCOW)}

Abstract. This article is aimed at studying the problems of increasing the role of family in society, stimulating childbearing, improving the socio-economic conditions of large families, improving the level and quality of their life. The state and the family must become partners that share risks and responsibility for the well-being of both the individual family and the state as a whole. The results of the study were obtained in Moscow and reflect above all its specificity. At the same time, they are significant in the all-Russian plan.

The information base of the article is the sociological survey of 2110 respondents, living in Moscow. The authors formulate the results in the form of proposals in the field of material security, health and medical care, education, social security, leisure, housing.

Keywords: large family, city, region, benefits, material security, housing, employment, health care, education, social services, leisure 